\section{EFFECT OF RADIAL ARTERY OR SAPHENOUS VEIN CONDUIT AS A SECOND GRAFT ON LATE CLINICAL OUTCOME AFTER CORONARY ARTERY BYPASS GRAFTING SURGERY} To the Editor:

We read with great interest the article by Zacharias and colleagues ${ }^{1}$ regarding late outcomes after radial artery (RA) versus saphenous vein (SV) grafting during reoperative coronary artery bypass surgery. We do not support their statement that RA versus SV grafting at reoperation was associated with a late survival benefit analogous to what had been previously reported by the same group ${ }^{2}$ when the RA was used as a second arterial conduit in primary coronary artery bypass grafting (CABG) surgery.

In that article ${ }^{2}$ data analysis was performed on a retrospective observational CABG series. The cumulative 0 - to 6-year survival was better for patients with RA conduits versus propensity-matched patients with SVs as a second conduit (925 patients in each group). It might be reasonable to assume that angiographic graft patency influenced survival. However, the angiographic RA conduit's patency $(1.8 \pm 1.4$ years to redo angiographic analysis) was $68.2 \%$, which is statistically not better $(P=.11)$ than the SV graft patency rate $(63.3 \%)$. The authors pointed out that patency comparison derived from the subcohort of restudied patients who received both

\footnotetext{
The Editor welcomes submissions for possible publication in the Letters to the Editor section that consist of commentary on an article published in the Journal or other relevant issues. Authors should: - Include no more than 500 words of text, three authors, and five references. - Type with double-spacing. - See http://jtcs.ctsnetjournals.org/misc/ifora.shtml for detailed submission instructions. - Submit the letter electronically via jtcvs.editorialmanager.com. Letters commenting on an article published in the JTCVS will be considered if they are received within 6 weeks of the time the article was published. Authors of the article being commented on will be given an opportunity of offer a timely response ( 2 weeks) to the letter. Authors of letters will be notified that the letter has been received. Unpublished letters cannot be returned.
}

RA and SV conduits, in which each patient served as his or her own control subject, has shown significantly better RA graft patency (SV graft angiographic failure rate of $41 \%$ vs $23.9 \%$ observed for RA conduits, $P=.039))^{2}$ Although we are discussing a second conduit of choice in a CABG cohort with an internal thoracic artery to the left anterior descending coronary artery (LAD), each patient can serve as his or her own control subject only if tested conduits (RA or SV) were randomly assigned to graft either the circumflex or the right coronary territory. Furthermore, target vessel stenoses, diameters, and territories of runoff (area of distribution) should be similar and determined in inclusion criteria. Although the authors are proponents of arterial grafting, we assumed that RA conduits were placed to the next best target other than the LAD. If RA conduits were all applied to the largest non-LAD target, the cross-sectional area of their runoff circulation would have been larger than that of the SV grafts performed, which could therefore be expected to fail more readily than the RA grafts. Furthermore, when the SV grafts are used only to the second-best target, patency is $90 \%$ at 5 years on optional angiograms and $80 \%$ at 9 years in the protocol-directed angiograms (prospective, randomized, single-center trial). ${ }^{3}$ Achouh and associates ${ }^{4}$ have recently reported a similar angiographic patency rate at 10 years after $\mathrm{CABG}$ surgery for both conduits $(83 \%$ of RA conduits vs $81 \%$ of SV grafts).

Hayward and coworkers ${ }^{5}$ concluded that use of the RA or SV for the second conduit during primary $\mathrm{CABG}$ did not significantly influence clinical outcome at 6 years. There was no significant difference in absolute survival in the RA group versus that seen in the SV group (similar number of patients, 16 deaths in each group, 4 deaths were cardiac in cause in the RA group vs 2 deaths in SV group). Unfortunately, the cause of death is unknown in the patient population of Zacharias and colleagues, ${ }^{1}$ and thus the death rate might be independent of cardiac factors.

Dusko Nezic, MD, PhD, FETCS

Aleksandar Knezevic, $M D, B c S$

Slobodan Micovic, $M D, B c S$

Department of Cardiac Surgery

"Dedinje"' Cardiovascular Institute Belgrade, Serbia

\section{References}

1. Zacharias A, Schwann T, Riordan C, Durham SJ, Shah AS, Engoren M, et al. Late outcomes after radial artery versus saphenous vein grafting during reoperative coronary artery bypass surgery. $J$ Thorac Cardiovasc Surg. 2010;139:1511-8.e4.

2. Zacharias A, Habib R, Schwann T, Riordan C, Durham S, Shah A. Improved survival with radial artery versus vein conduits in coronary bypass surgery with left internal thoracic artery to left anterior descending artery grafting. Circulation. 2004;109: 1489-96.

3. Hayward P, Gordon I, Hare D, Matalanis G, Horrigan ML, Rosalion A, et al. Comparable patencies of the radial artery and right internal thoracic artery or saphenous vein beyond 5 years: results from the Radial Artery Patency and Clinical Outcomes trial. J Thorac Cardiovasc Surg. 2010;139:60-7.

4. Achouh P, Boutekadjirt R, Toledano D, et al. Longterm (5- to 20-year) patency of the radial artery for coronary bypass grafting. $J$ Thorac Cardiovasc Surg. 2010;140:73-9.

5. Hayward P, Hare D, Gordon I, Buxton B. Effect of radial artery or saphenous vein conduit for the second graft on 6-year clinical outcome after coronary artery bypass grafting. Results of a randomised trial. Eur J Cardiothorac Surg. 2008;34:113-7.

doi:10.1016/j.jtcvs.2010.01.047

\section{Reply to the Editor:}

My coauthors and I reviewed the letter by Nezic and colleagues ${ }^{1}$ related to our recent article in the Journal. ${ }^{2} \mathrm{Al}-$ though we appreciate their opinion, we were surprised that the letter at issue ${ }^{1}$ did not discuss our article ${ }^{2}$ per se. Rather, it used our recent article as a springboard to jump back to a 2004 article from our group, ${ }^{3}$ making essentially the same point as in several previous letters that have discussed other articles comparing the effects on late coronary bypass surgery $(\mathrm{CABG})$ outcomes of use of radial artery (RA) versus saphenous vein (SV) as a second grafting conduit. We stand by our statement that the survival benefit observed with RA versus SV grafting 